\title{
Optimisation of paste thickening at the Yara Siilinjärvi plant
}

\author{
E Ruhanen Yara Siilinjärvi, Finland \\ M Kosonen Outotec Oyj, Finland \\ S Kauvosaari Outotec Oyj, Finland \\ B Henriksson Outotec Oyj, Finland
}

\begin{abstract}
The Yara Siilinjärvi plant is located in central Finland. The site consists of a mine, two sulphuric acid plants, one phosphoric acid plant, one nitric acid plant and one NPK fertiliser plant. The Siilinjärvi mine produces about $1 \mathrm{Mt}$ of apatite concentrate, which creates approximately $10 \mathrm{Mt}$ of tailings per year.

At the beginning of 2017, tailings handling in Yara Siilinjärvi was brought into a new era, when the conventional tailings storage facility was replaced with a new tailings treatment plant. The new high-density tailings disposal system with two deep cone-type paste thickeners increased the percentage of solids in the slurry from 45-48\% to 66-69\%, making it possible to deposit as paste. This extended the lifetime of the current tailings storage facility by 15 years - from 2020 until 2035.

The rheology of the tailings in Siilinjärvi is unique, due to the minerology of the slurry. In particular, the high content of coarse mica makes thickener operation challenging and makes high-density pumping sensitive to disturbances. Therefore, the importance of process control cannot be underestimated. An advanced control system is needed to maintain process stability and the desired operation point in varying running situations.

This paper presents the results from applying a multivariable, optimising control strategy to two paste thickeners at the Yara Siilinjärvi plant. The presented solution is based on a separate advanced control tools (ACT) platform, and it can be cost-effectively utilised with any customer distributed control system/ programmable logic controller (DCS/PLC) system available. With the ready-made application package, implementation is straightforward, and only a minimal amount of system-specific tailoring is needed. The ACT system in Yara is highly integrated with the plant DCS, so that the operators have full access to the user interface, alarms, interlockings, history data and documentation through the DCS displays.

Long-term follow-up shows that with the optimising control, the Yara paste thickeners can consistently run with underflow solids content of $66-68 \%$ to average beach slope angles of $3.5^{\circ}(6.1 \%)$ in the tailings disposal area. Additionally, this control system facilitates the minimum use of flocculant, which means 10-20\% savings in the flocculant costs. Robust thickener operation also leads to trouble-free high-density pumping and high availability of the paste plant.
\end{abstract}

Keywords: tailings, paste, thickening, process control, optimisation

\section{Introduction}

Traditionally, thickener controls are implemented as single loop proportional integral (PI) controllers in a plant's automation system. Many of these installations suffer from poor process control, because single loop controllers are not optimal to handle the slow and complicated dynamics of the thickening process. To overcome these limitations, a novel approach to utilise multivariable model predictive control for optimising thickener performance has been developed (Kosonen et al. 2017). 
The Yara Siilinjärvi plant is owned by Yara International, a Norwegian chemical company, which is a global mining company specialising in agricultural products and environmental protection agents. Yara Siilinjärvi is Western Europe's only apatite mine, producing fertilisers, phosphoric acids and other industrial chemicals. Site annual production is $1 \mathrm{Mt}$ of apatite concentrate, which creates approximately $10 \mathrm{Mt}$ of tailings.

To extend the lifetime of the existing tailings storage area, Yara replaced the conventional tailings storage facility with a new tailings treatment plant. The new high-density tailings disposal system with two deep cone-type paste thickeners increased the percentage of solids in the slurry from 45-48\% to 66-69\%, making it possible to deposit it as a paste. This extended the lifetime of the current tailings storage facility by 15 years, from 2020 until 2035.

This paper presents the results from applying optimising control strategy to the two paste thickeners at the Yara Siilinjärvi tailings plant. Firstly, we outline the background for the paste plant project and general process layout, and challenges for process control are introduced. We then present the actual control implementation and system structure, and the work required for commissioning and start-up are discussed. Finally, results from the controls performance follow-up are presented, and the improvements gained from optimising the control strategy are discussed.

\section{Yara Siilinjärvi paste plant}

\subsection{Paste plant project}

Extending the lifespan of the 1,150 hectares tailings storage facility has been studied at Siilinjärvi for a long time. The aim has been to use the same tailings area footprint, without any new land purchases or major dam increases. One important aspect to study was the possibility of using new technologies, especially thickened tailings technology (Ruhanen 2014).

After initial laboratory tests, the target was set to increase the solids content of the tailings slurry from $45-48 \%$ to $70-72 \%$ (by mass) and thereby increasing the slope angle of the tailings deposit. After performing $1 \mathrm{~m}$ pilot unit thickening tests, it was decided to build a large 100 tph pilot plant with a $14 \mathrm{~m}$ diameter thickener in the tailings area. Large pilot trials were completed in 2013-2014. After some iterations during the pilot stage, a final working configuration was found and encouraged after successful pilot tests. Consequently, the planning of a full-scale plant was started at the end of 2014 (Ruhanen 2014).

Building of the plant commenced at the end of 2015, and at the beginning of 2017 the paste plant was installed and commissioned with a $6.6 \mathrm{~km}$ tailings feed pipeline between the concentrator and the paste plant. The final target set for the engineering, procurement and construction project was to achieve a $68-70 \%$ solids underflow and at least $2^{\circ}(3.5 \%)$ beach slopes, which would extend the tailings pond lifespan from 2020 until 2035.

\subsection{Process layout}

The main components in the paste plant are the feed tank, two deep cone-type paste thickeners, three positive displacement (PD) pumps, and three paste discharge lines to the tailings disposal area. The total plant feed is $1,200 \mathrm{tph}$, which is divided equally to the two $30 \mathrm{~m}$ paste thickeners. As a solids tonnage flux rate, this means $0.85 \mathrm{t} / \mathrm{m}^{2} / \mathrm{hr}$. The basic operating principle is that one thickener always feeds one PD pump, which instead feeds one discharge line (Figures 1 and 2). 


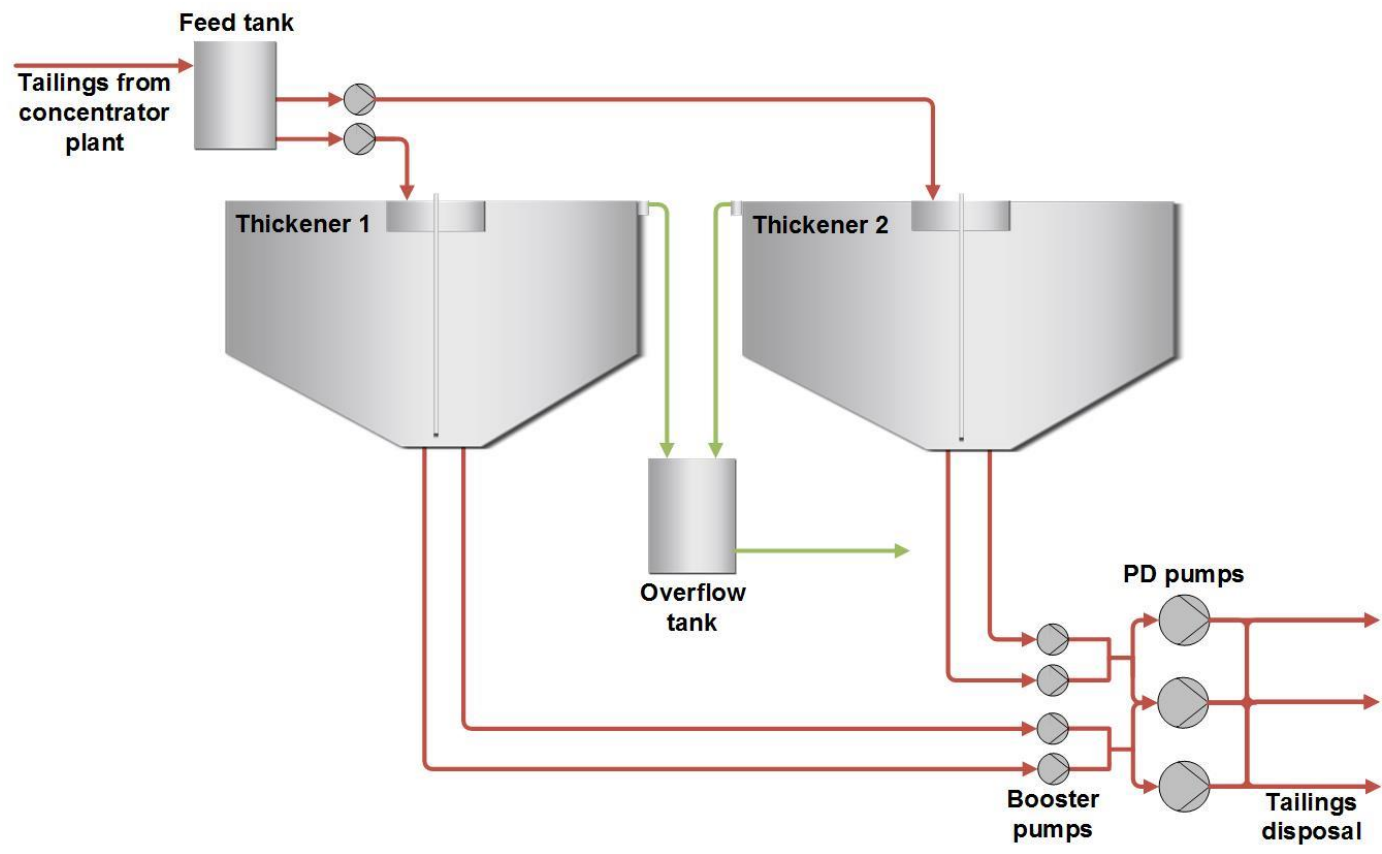

Figure 1 Yara Siilinjärvi paste plant process layout

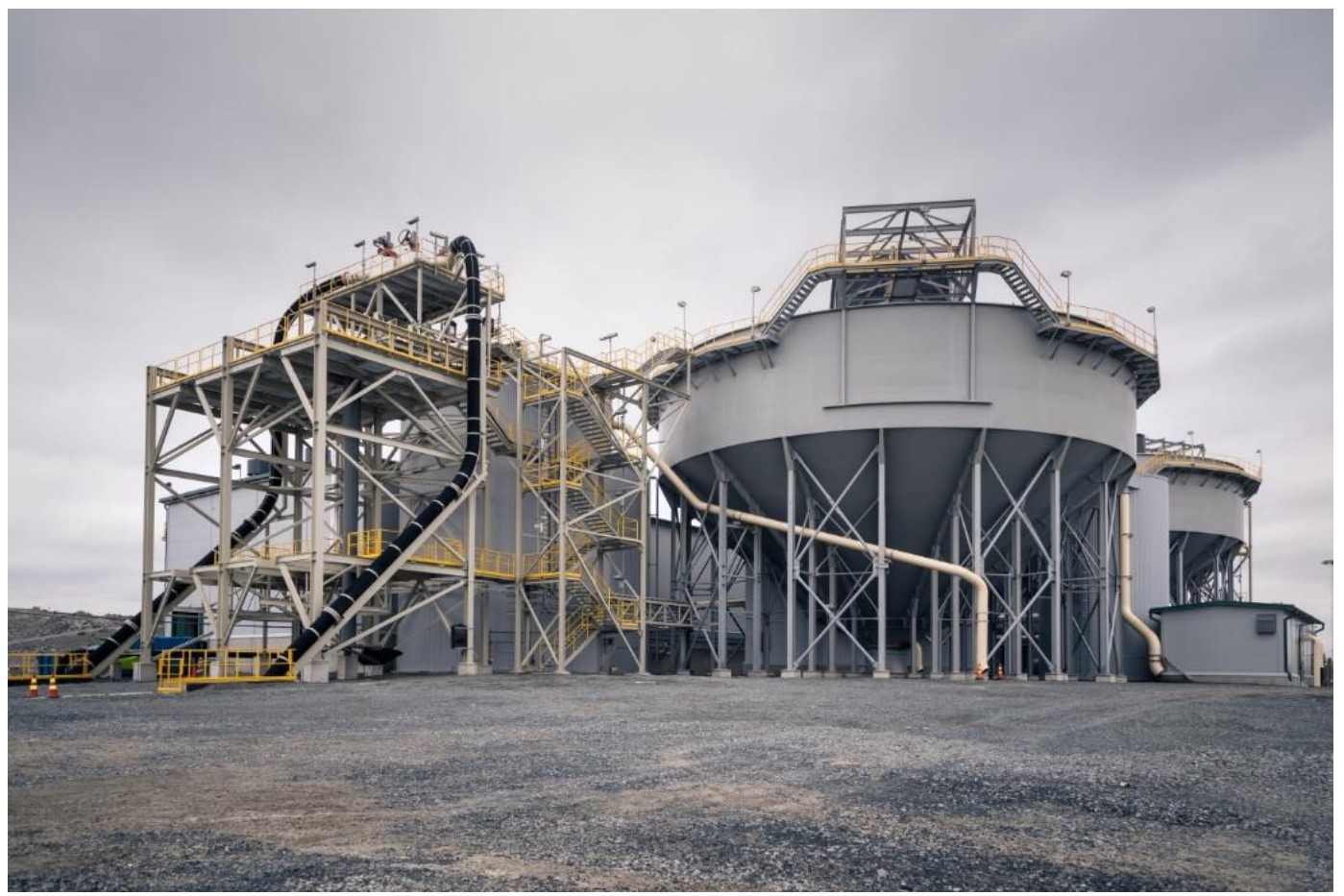

Figure 2 Yara Siilinjärvi paste plant

The system is built to be flexible, so that there is always one PD pump and one discharge line on standby. This ensures high plant availability and ensures uninterrupted operation, e.g. in situations where one discharge line is under extension. 


\subsection{Challenges for process control}

The rheology of the tailings sand in Siilinjärvi presents challenges for process control, because the minerology varies significantly on a daily basis. The overall tailings sand mineralogical composition is presented in Table 1.

Table 1 Mineralogical composition of the tailings sand (Aaltonen 2014)

\begin{tabular}{lll}
\hline Mineral & Percentage & Variation \\
\hline Apatite & $1.2 \%$ & $0.7-10 \%$ \\
Carbonate minerals (calcite, dolomite) & $20 \%$ & $10-35 \%$ \\
Phologopite mica & $74 \%$ & $60-85 \%$ \\
Other silicates & $5 \%$ & $1-10 \%$ \\
\hline
\end{tabular}

In general, tailings sand is relatively coarse, but it varies daily. Particles coarser than $300 \mu \mathrm{m}$ are mostly flaky mica, with an average thickness of roughly $20 \mu \mathrm{m}$. Particle size distribution of the tailings sand is shown in Figure 3.

\section{Particle size distribution}

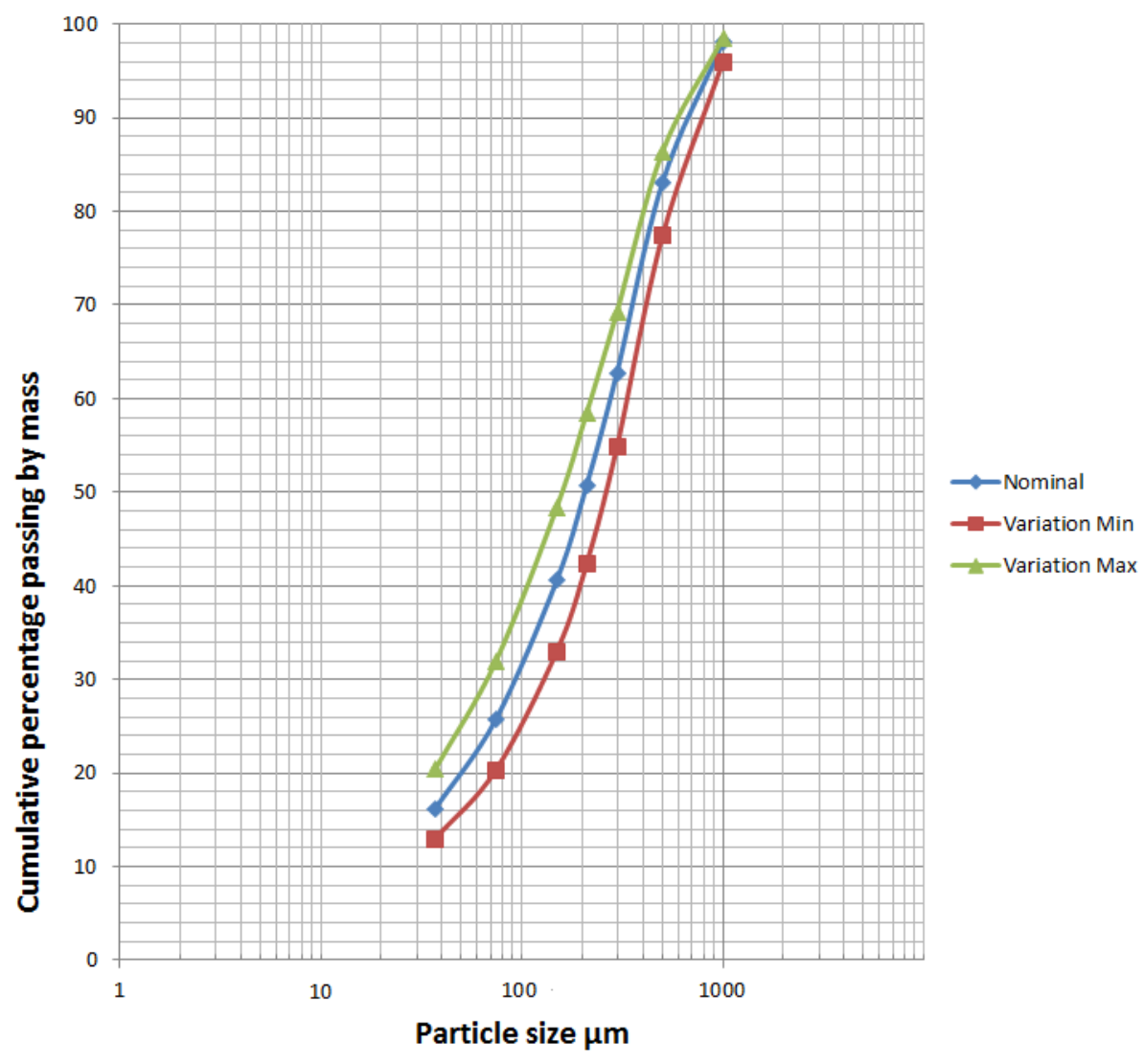

Figure 3 Particle size distribution of the tailings sand (Aaltonen 2014)

In particular, the high content of coarse, flake-like mica adds its own characteristics to the process and strongly influences both the thickening and pumping performance. For example, when the ore is extracted from areas with high quantities of sheared ore, the particle size distribution is very fine. Thus, the material is more difficult to compact, but relatively easy to pump to the disposal area. During these situations, the thickener needs to be run with very high inventory levels, even at $95 \%$, to get the required density and beaching properties. On the other hand, when the material is coarser, it compacts easily, and the required density levels can be easily reached with inventory levels of $55-60 \%$. In these situations, however, there are 
high pressure losses in pumping, and the rake torque tends to get high, so the available operating window is limited (Ruhanen 2014).

The biggest disturbances to the paste plant feed are caused by the crushing and milling circuits at the main plant. Crushers are operating with a $24 \mathrm{hr}$ stockpile and the biggest changes occur when the stockpile and hence the incoming ore type is changed. In the milling, conversely, each section has to be shut down for a 1-8 $\mathrm{hr}$ period each week to charge the new rods. This reduces the paste plant input mass flow remarkably, which causes major disturbance to the plant. Although both of these incidents can be forecast with some accuracy, the actual influence and duration of disturbance is difficult to estimate. Therefore, the plant control system should be able to smoothly handle both the variation in the ore type and in the incoming mass flow.

The paste plant is located $6.6 \mathrm{~km}$ away from the main concentrator plant, and the operators in the main plant have no visual contact with it. Currently, the paste plant has its own personnel, but in the long-term, the target is to operate and maintain the plant with the personnel from the main plant. This requires the plant to be fully controllable remotely and emphasises the importance of optimised process control. An advanced control system is needed to maintain process stability and the desired operation point in varying running situations.

\section{Optimising control for thickeners}

In this chapter, a novel approach to utilise a multivariable model predictive controller (MPC) to control paste thickeners in the Yara Siilinjärvi plant is presented. In the beginning, the MPC control algorithm is discussed on a general level. After this, a dedicated Outotec advanced control tools (ACT) application platform used in the implementation project is introduced. Then, a more detailed controller structure implemented during the project is described. Finally, the work needed for the commissioning of controls and start-up is discussed.

\subsection{Control algorithm}

The thickener control application uses the MPC algorithm. Model predictive controller is an advanced process control method which has been used in chemical plants and oil refineries since the 1980s. In recent years, it has spread to other process industries, and nowadays it is considered a standard method for control processes with a multivariable character and complex response dynamics (Maciejowski 2002; Kosonen 2004; Wikipedia 2017a).

Model predictive controller control is based on the process response models, which are typically obtained by performing process trials or simulating the process responses. These process models are used to predict process behaviour in the future. Based on these predictions, a set of future control actions are calculated to drive process to the desired set points. Thereafter, the initial calculated control actions are implemented, and the whole calculation procedure is repeated during the next control cycle (Figure 4).

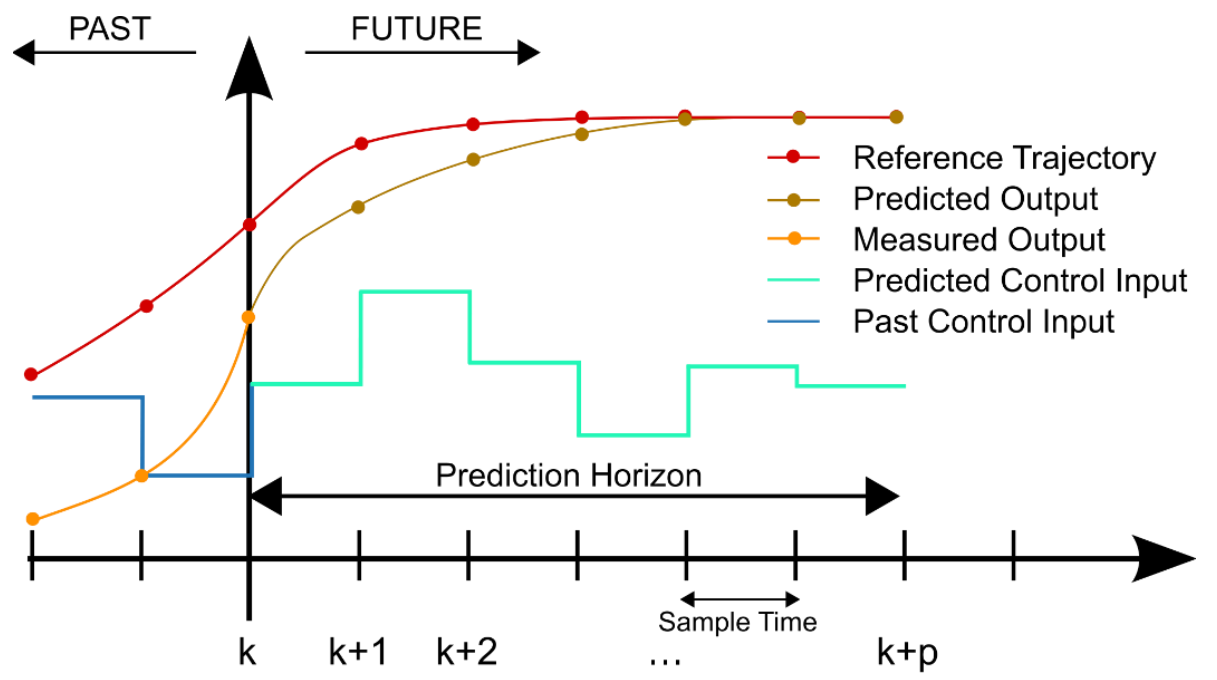

Figure 4 Model predictive control principle (Wikipedia 2017a) 
In a multivariable MPC, there are no direct manipulated variable (MV) versus controlled variable (CV) relationships, meaning that one specific actuator, such as the underflow pump speed, is adjusted purely to control one specific variable, e.g. underflow density. Instead, controller outputs are calculated as an optimised result of the cost function, which can, for example, have the following form (Bemporad et al. 2015):

$$
J(k)=J_{y}(k)+J_{u}(k)+J_{\Delta u}(k)+J_{c}(k)
$$

where:

$$
\begin{aligned}
& \mathrm{J}(k)=\text { total value of cost function at discrete time instant } k . \\
& \mathrm{J}_{\mathrm{y}}(k)=\text { penalty for predicted control errors of all CVs. } \\
& \mathrm{J}_{\mathrm{u}}(k)=\text { penalty for actuator position tracking (all MVs). } \\
& \mathrm{J}_{\mathrm{Uu}}(k)=\text { penalty for actuator move suppression (all MVs). } \\
& \mathrm{J}_{\mathrm{C}}(k)=\text { penalty for violating given constraints in CVs or MVs. }
\end{aligned}
$$

In other words, MPC control has the in-built ability to prioritise between different controlled variables and inherently pay attention to the limitations in the process. Since the control actions result from minimising the cost function, the control is truly an optimising controller which will always produce an optimal solution to the control problem (Equation 1). Tuning parameters of the system are the limitations given to the various $\mathrm{CVs}$ and MVs and weighting factors included in partial cost functions in Equation 1. Control parameterisation highly affects the final behaviour of the controller.

\subsection{System structure}

A model-based controller was implemented by using the Outotec ACT platform, which is a dedicated environment developed especially for advanced process control solutions. In general, ACT platforms include the following (Figure 5):

1. Engineering tools for application development.

2. An ACT engine to run the control application.

3. History database for data collection and analysis.

4. Data interfaces to external systems.

5. User interface for operators.

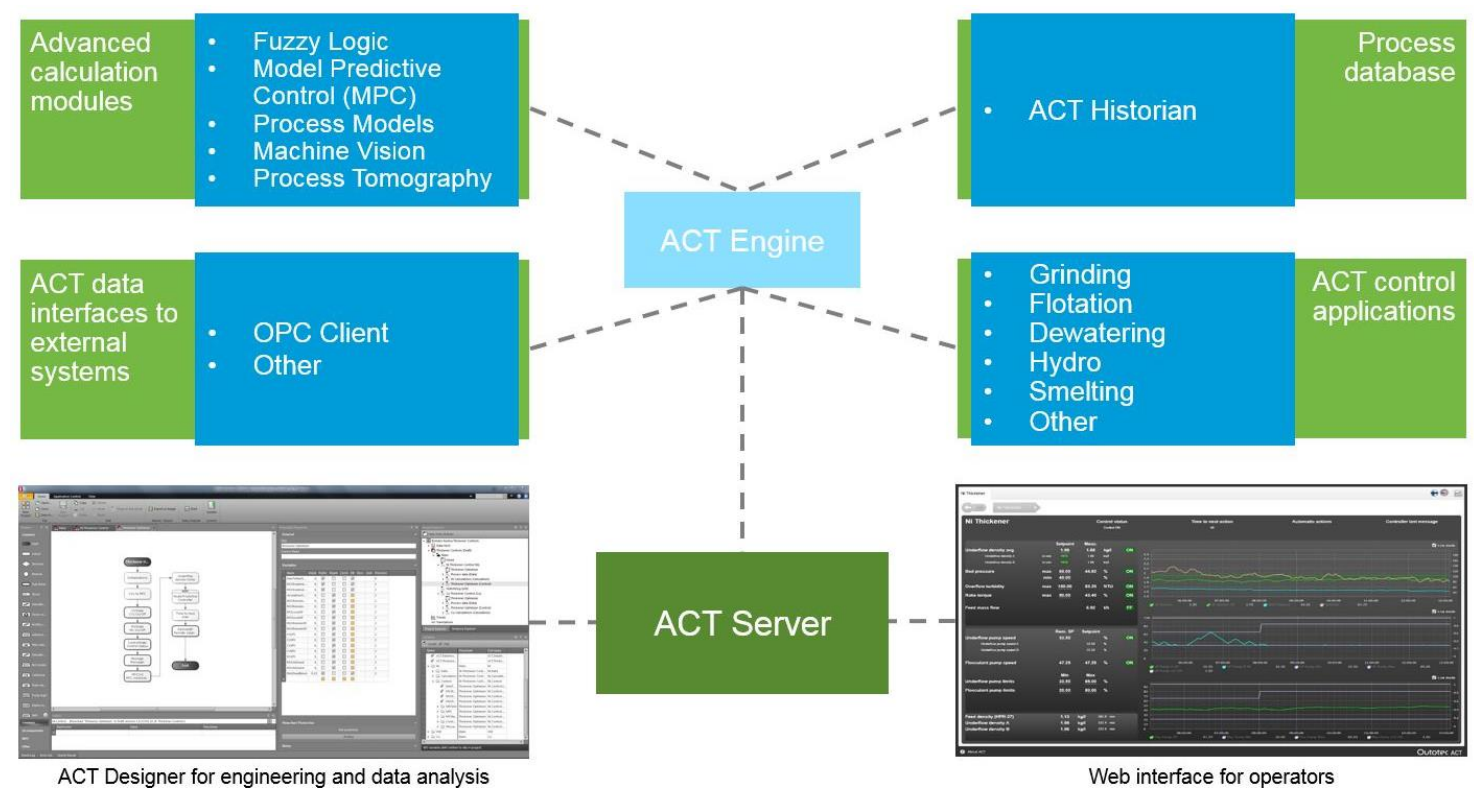

Figure 5 Outotec ACT platform 
Tasks 1-4 are executed on a dedicated ACT server computer, which is connected to the DCS system with a suitable data interface. Typically, a separate ACT client computer is a user interface (task 5), so the operators do not have direct access to the ACT server.

In the Yara paste plant project, a high level of system integration was desired. Therefore, the separate ACT operator client was excluded from the delivery, and a similar interface was built into the customer's DCS system. This meant that the controller user interface, alarms, interlockings, history data and instructive documentation were all implemented in the customer's DCS. This ensured that the operator had the full functionality available by using the same user interface also used otherwise for plant control (Figure 6).

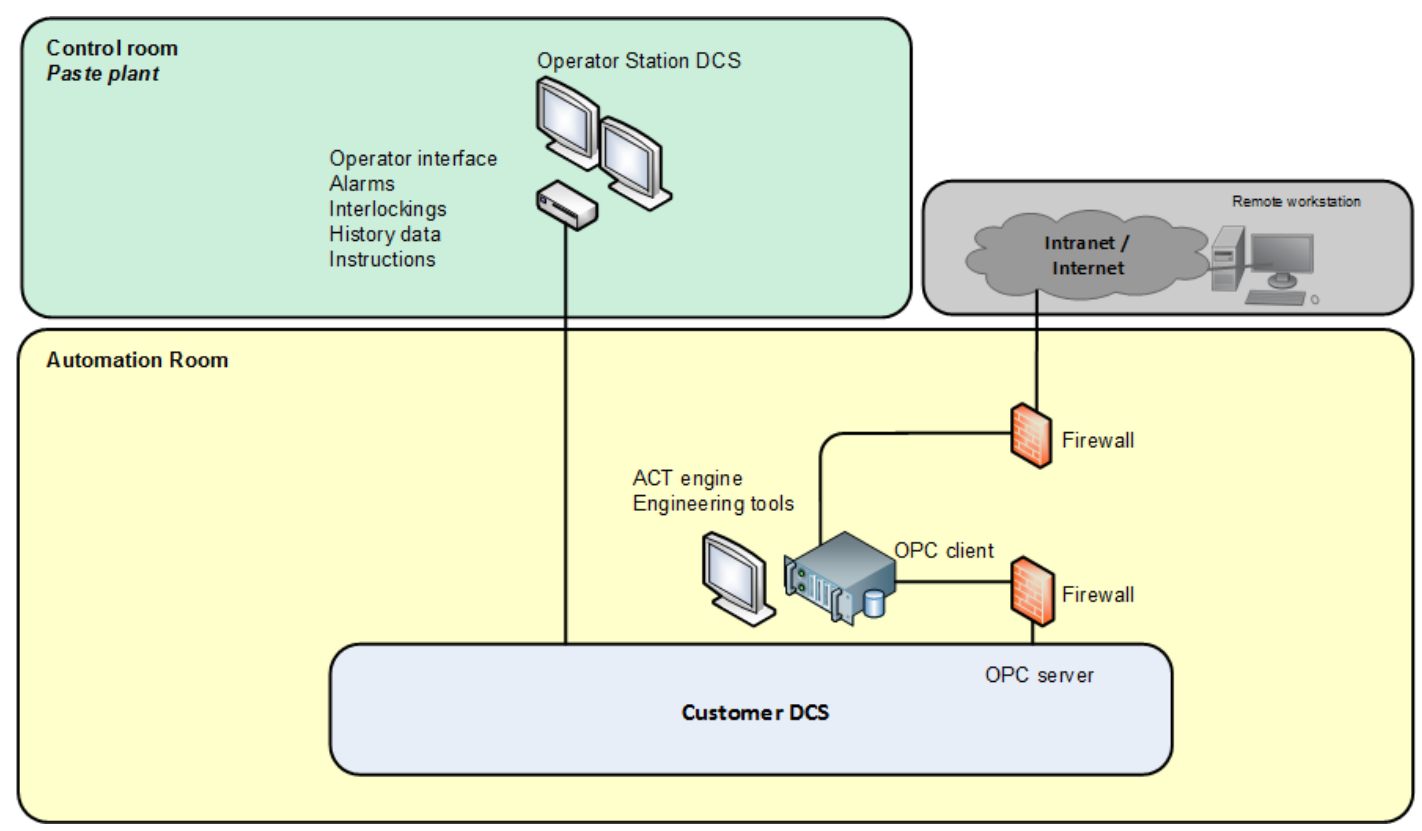

Figure 6 System layout

A dedicated ACT server accommodated the engineering environment and executed the calculation engine for model-based controls. This approach ensured that a ready-made application package with full ACT features could be used for the implementation of controls, which minimised the need for project-specific tailoring. Communication between the ACT server and DCS was done with an OPC data access datalink (Wikipedia 2017b). The ACT server also included a remote connection to the Outotec network, so that the controller performance monitoring, tuning, and support could also be done remotely (Figure 6).

\subsection{Controller set-up}

The structure of the optimising controller is shown in Figure 7. The controlled variables in the system are:

- Underflow density $\left(\mathrm{kg} / \mathrm{m}^{3}\right)$.

- Overflow solids content (\%).

- Bed mass (\%).

- Bed level (m).

- Rake torque (\%).

From these variables, underflow density was selected to be a primary control variable, which has a precise target value and the highest priority during normal operation. This was a natural choice, because the main target of the whole paste plant is to produce stable and high enough underflow solids content, thereby ensuring stable pumping and good tailings beaching properties. 


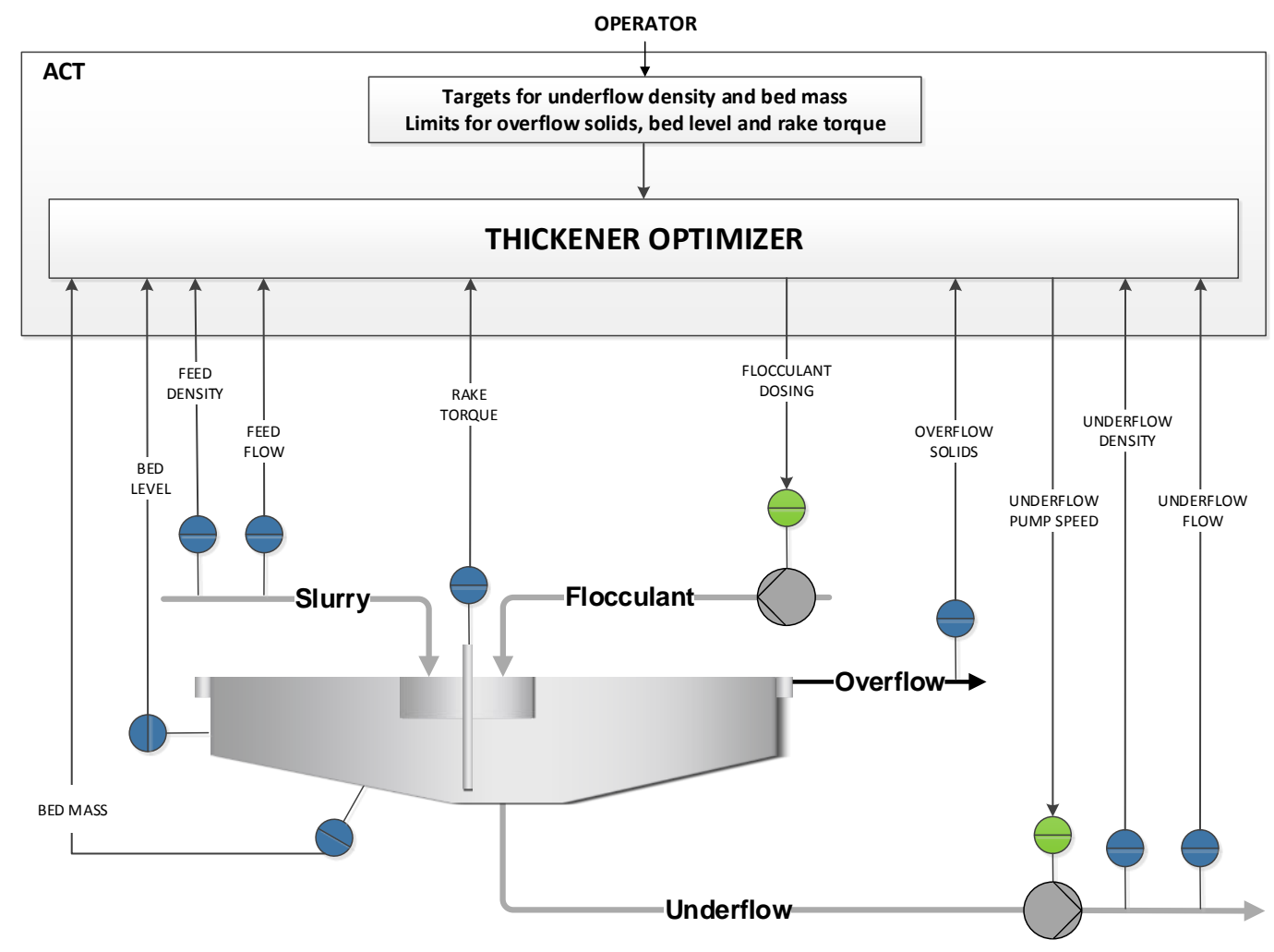

Figure 7 Optimising control for thickeners - system structure

Overflow solids is the second most important variable describing the cleanliness of the recovered water. As such, it is not important to control solids to a certain, precise target value, but to avoid excessive amounts of solids in the overflow for longer periods of time. Simultaneously, the flocculant dosage should be limited to a certain operating range, ensuring trouble-free thickener operation. Overall, the system should run with minimal flocculant dosage to minimise the plant operating costs.

Bed mass is measured by a pressure measurement gauge mounted at the bottom of the thickener tank. The sensor actually detects pressure in $\mathrm{kPa}$, but it can be transformed to '\% bed mass' units for easier interpretation. Together with the electro-mechanical bed level plumb sensor, they indicate the inventory level of the thickener and provide information about the current operating point (Parker et al. 2016). Therefore, the controller should keep these variables within a certain operating range, but not aim for a specific target value. The same principle applies also to the rake torque, which indicates the forces directed to the raking mechanisms. Torque is taken into account as a constraint in the optimisation, so that when operating at high torque levels, control actions leading to critical rake loads are avoided.

Information from the thickener feed line, i.e. input flow rate and slurry density, are also used in the controller set-up. Since the input mass flow to the tailings thickener can vary quite rapidly depending on the operations in the main concentrator plant, it is important to react efficiently to sudden changes and maintain the highest quality underflow in all situations. When the controller has information from the feed line, more timely corrections are made, and smaller disturbances are caused to the thickening process.

The control manipulates the underflow pump speed and flocculant dosage. As discussed in Section 3.1, model-based controllers typically have many ways to influence the behaviour of the manipulated variables. The movement speed of the actuators can be limited, actuators can have desired target levels, or the actuator operating range can be limited. 


\subsection{Controls commissioning and start-up}

During project implementation, the optimising controllers were commissioned on both of the thickeners. Overall, the commissioning work was divided into three select phases.

The first phase included the ACT system set-up, modifications to DCS loops and user interface, and setting up the communication between the ACT system and the DCS. Normally, this is quite a straightforward task, because the thickener controls package comes as a ready-made application, and the need for project-specific tailoring is low. In the Yara case, however, a higher level of system integration was desired, so that user interface, alarms, interlockings, history data and instructive documentation were all implemented in the DCS.

The second phase comprised the actual commissioning of the optimising control system. This included the process trials and modelling needed to create models for the MPC controller. This required a stable operation point and a running situation where excitation trials could be done with the production process. Additionally, this phase also included the actual controller start-up, initial tuning work and operator training.

The final part of the start-up was the fine-tuning of the controls and follow-up work. During this period, controllers were run continuously and system performance was closely followed on a daily basis. Based on the observations and operator's comments, the control tuning parameters were adjusted to sharpen the performance. The major part of this work was completed remotely by using remote access to the ACT system. This was a very time-efficient and agile way of working, and will also be used to provide remote support in the future.

In total, the controls commissioning was completed in six weeks, with half the time spent on site and half working remotely. Overall, start-up proceeded very smoothly, and operators adopted the system very quickly. As of October 2017, the controls have been in use for five months, during which the overall controls usage rate has been over $92 \%$. In practice, this means that the controls are in use all the time, and only exceptional situations are handled with manual control.

\section{$4 \quad$ Implementation results}

In this section, results from applying the optimising control strategy to two paste thickeners are presented. First, results from the closed loop response test showing the overall system dynamics are presented. Then, results from the long-term performance study are presented. Finally, the operational results achieved with the advanced control strategy are discussed.

\subsection{Closed loop performance}

The standard way to test controller performance is to perform a closed loop step response test. This means that the controller set point is step-wisely changed in a stable running situation, and the responses to controlled variables are monitored. Figure 8 shows a closed loop test done with the optimising controller in Thickener 2. In the test, the density set point was increased by $10 \mathrm{~kg} / \mathrm{m}^{3}$ from 1,770 to $1,780 \mathrm{~kg} / \mathrm{m}^{3}$, and the response to controlled variables was monitored. 

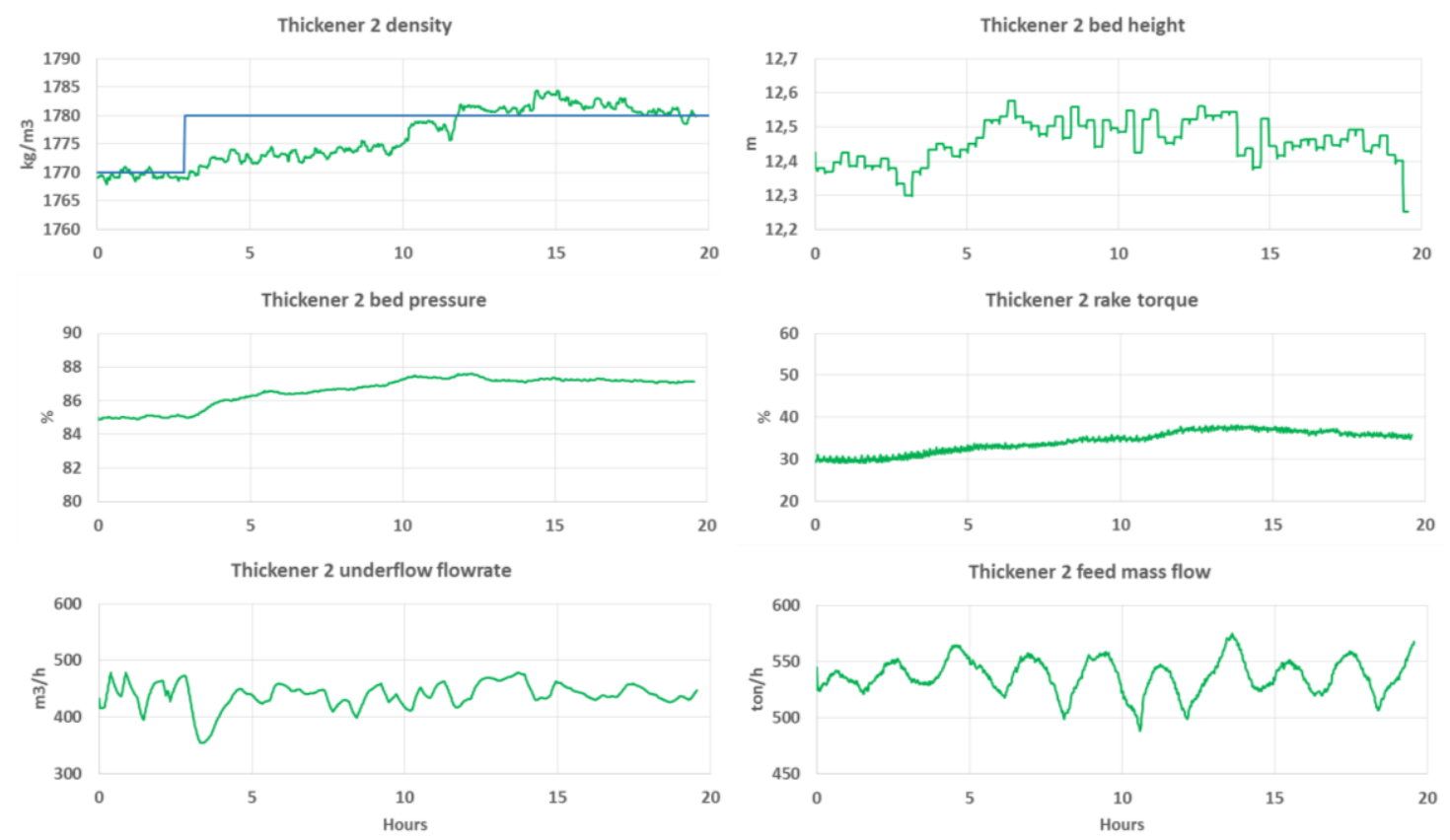

Figure 8 Underflow density change with optimising controller (green line is measured value, blue line is target value)

Figure 8 shows that the control responds to the set point change very well. The controller set point was changed at a time instant of three hours, after which the controller immediately adjusts the underflow flow rate to drive the system to another operating point. After half an hour, when the first impression of response can barely be seen in the controlled variables, the controller drives the underflow flow rate back to its original level. The actual response to density happens several hours later between 9-12 hours, when the density measurement reaches the set point.

This example shows quite nicely the basic challenge of paste thickener control. Thickening is an integral process and the compacted bed has a 'memory', so that the changes in the input-output mass balance are seen several hours later in the underflow. Long response dynamics make this process difficult to control with traditional PI control loops, and operators have difficulties in understanding long dynamics when performing manual operations. However, with the multivariable model-based control, both the system dynamics and interactions in the process are taken into account, so that a more precise control result is achieved.

This example also shows the importance of measurements in the incoming feedline. During the observed period, there is a continuous 50 tph variation in the incoming mass flow. Since the controller has information from the incoming line, it adjusts the underflow flow rate to compensate for the incoming disturbance, and very little variation is seen in the density and other controlled variables.

\subsection{Long-term process variability}

As of October 2017, the optimising controls have been running in the Yara paste plant for five months. Experiences have been good, and operators have adopted the controls well into their daily toolkit. Since start-up, the controls have been in continuous use. It is only during exceptional situations, such as underflow line flushing or maintenance work, that manual operations are needed. Overall, the controls usage rates have been over $92 \%$.

As an example, Figure 9 presents the optimising control performance in Thickener 1 between June and August 2017. During the observed 50 day period, the plant was in continuous operation without any shutdowns. The feed mass flow to Thickener 1 has varied between 450 and 650 tph, and in many situations there have been sudden, over 100 tph changes in the feed flow. Control off periods have been removed from the data. 

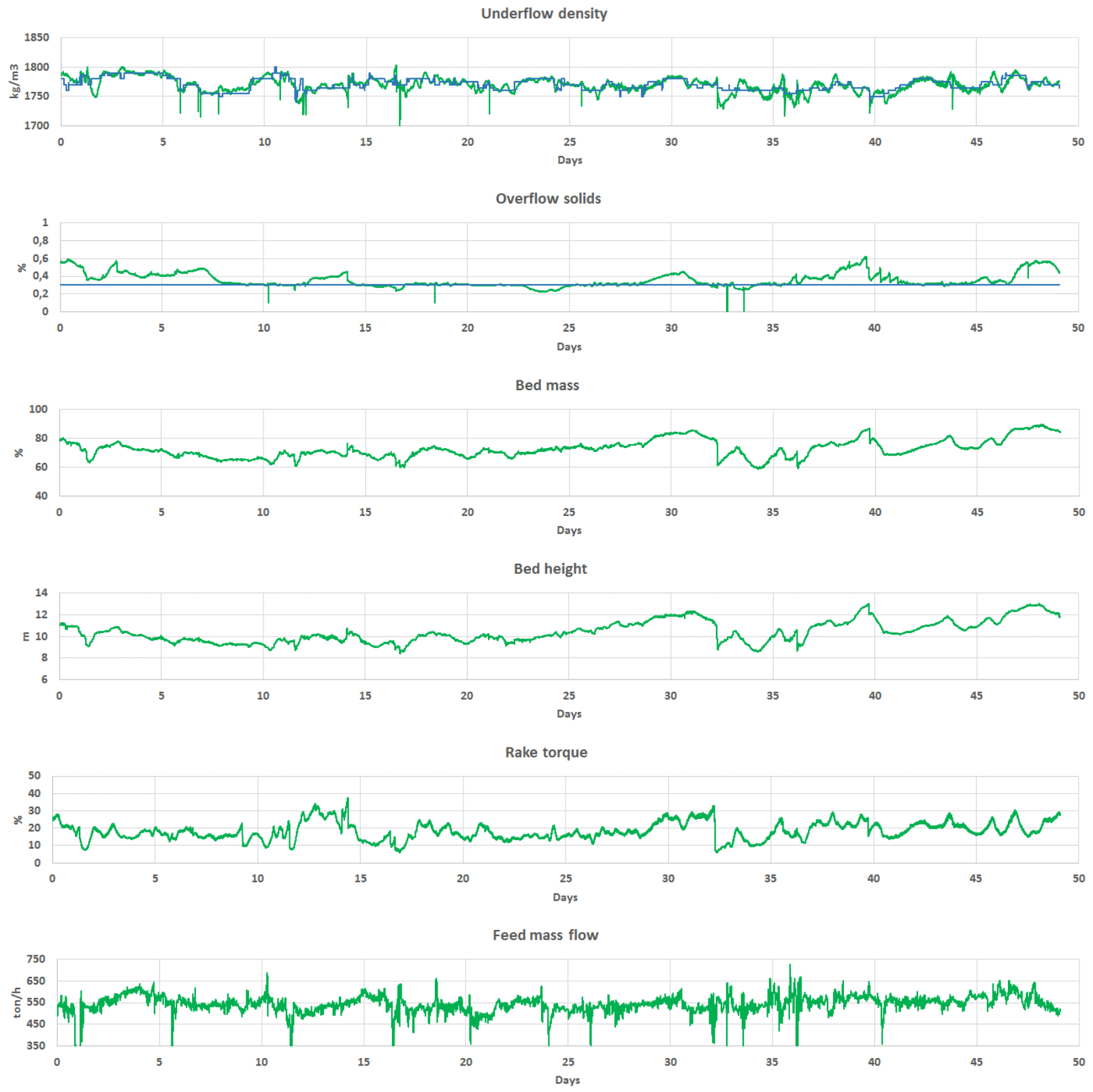

Figure 9 Long-term process variability of Thickener 1 (the green line is the measured value, the blue line is the target value)

Underflow density is the main controlled variable. The basic operating principle is to run the system with the highest possible density that still ensures trouble-free pumping. In practice, this means that the operator adjusts the density target value in accordance with the observed pumping behaviour and the visual appearance of discharged slurry. Because the paste plant is operating very close to the corner point in the solids content versus yield stress curve (Paterson 2004), even a very small $10-20 \mathrm{~kg} / \mathrm{m}^{3}$ change in density makes a remarkable difference in pumping resistance.

As seen from Figure 9, the density control is working very well. Most of the time, the instantaneous density value (one minute sampling interval) is very close to the target value, and even after big, sudden feed changes, there is only minor deviation from the set point. Statistically, the two-sigma value for control error is $20 \mathrm{~kg} / \mathrm{m}^{3}$, meaning that during $95 \%$ of the entire control operating time the underflow density is within a target window of $\pm 20 \mathrm{~kg} / \mathrm{m}^{3}$ from the set point. As a solid content, this means an operating window of $\pm 0.85 \%$. 
Another main controlled variable is the overflow solids. In Yara, the target is to have solids content near $0.3 \%$. As can be seen from Figure 9, this succeeds most of the time, but sometimes there are longer periods when the given target is exceeded. The reason for this is that sometimes an extremely fine material comes to the thickener. This material responds weakly to the flocculant and hence settles poorly. Therefore, when there is a lot of very fine material in the process, the overflow solids tend to increase.

The other controlled variables are the bed mass, bed level and rake torque. These variables are not strictly controlled, but they all have their preferred operating points. Therefore, as can be seen from Figure 9 , these variables can float quite freely, but if they are going to escape their operating window, the control drives them back to the desired level. As discussed in Section 2, this kind of behaviour is very straightforward to implement in the model-based control, but with single loop PI controllers, this would require complicated rule-based interlockings.

In Section 2.4, we mentioned that due to the changing ore type and minerology, the target density level is obtained with very different thickener inventory levels. This can be seen very clearly from the density and bed mass trends. At those times, when the ore type remains the same, bed mass and density correlate well with each other. However, sometimes when the ore type changes, the trend lines differ from each other (e.g. time interval $40-45$ days). This also assures that a constant bed mass does not guarantee a constant density.

\subsection{Operational results from advanced control strategy}

One of the key targets set for the Yara paste plant project was that the plant should operate continuously with an underflow solids content between 68 and 70\%. The realised solids contents in June to August 2017 are shown in Figure 10. As seen from the trend lines, both thickeners operate inside the operating window of $66-68 \%$. The reason why the realised operating values are slightly lower than the original targets is that the targeted beach slopes are exceeded already with this operating range. Hence, there is no need to reach for higher solids content. Average solids content in February to November 2017 was $67.5 \%$ and the overall solids content operating range was $66-69 \%$. The main variation comes from density set point changes done by the operator. In Figure 10, the solids content target value calculated from the actual density target is shown as a blue line and the measured value with a green line.
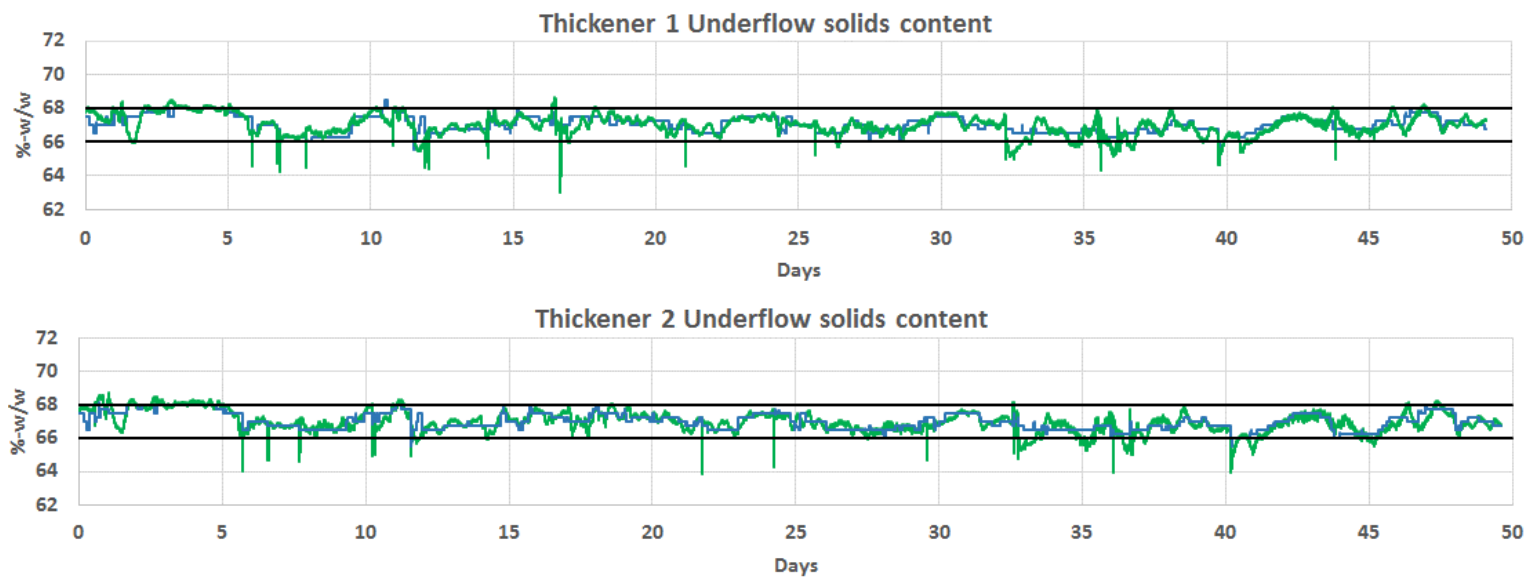

Figure 10 Long-term solids content variability (the green line is the measured value, the blue line is the target value calculated from the density target)

Before the installation of the advanced controls, the Yara paste plant used a single loop bed mass controller as the main tool to control underflow quality. As such, the controller was working well, but it was rather challenging for the operators to recognise situations where a major change in the thickener inventory level is needed. Therefore, the multivariable control is much easier to operate. The operator sets the density set point and the control automatically adjusts the inventory level to the required level. Other situations, which are now much easier to handle, are the sudden, large changes in the feed mass flow. For example, the shutdown of one milling section in the concentrator plant drops the feed to the paste plant considerably. 
Nowadays, the control normally handles these disturbances lasting a few hours automatically, without any manual intervention from the operators.

Discharge line pumping pressure losses vary between 2 and $8 \mathrm{kPa} / \mathrm{m}$ depending on feed characteristics. Sometimes the losses can go higher for short periods of time. Overall, the pumping performance has not been a major issue during the past nine months of operation, but in some situations, extra underflow dilution is used to alleviate the high peaks in the pressure. For its own part, the optimising controller helps with this, because the control keeps the process strictly in its operational window. Hence, the system is easier to operate and fewer manual corrections from operators are needed.

One of the features of the optimising controller is that it tries to run the system with the lowest possible flocculant dosage. If the performance of controlled variables does not require a high dosage, the control gradually reduces the amount of flocculant. On the other hand, when more flocculant is needed, the dosage level is increased. Typically, this kind of control philosophy leads on average to lower consumption of chemicals. This happened in Yara, where the overall flocculant consumption was reduced by $10-20 \%$ compared to a system where the flocculant is only dosed proportionally to the incoming feed mass flow. Since the overall tonnage is high, this means remarkable savings in the plant operating costs.

Currently, nine months after the start-up, the paste plant has reached a consistent performance level. Underflow solids content is kept continuously in the required operating window, and the achieved average beach slope angles are over $3.5^{\circ}$ (Figure 11 ).

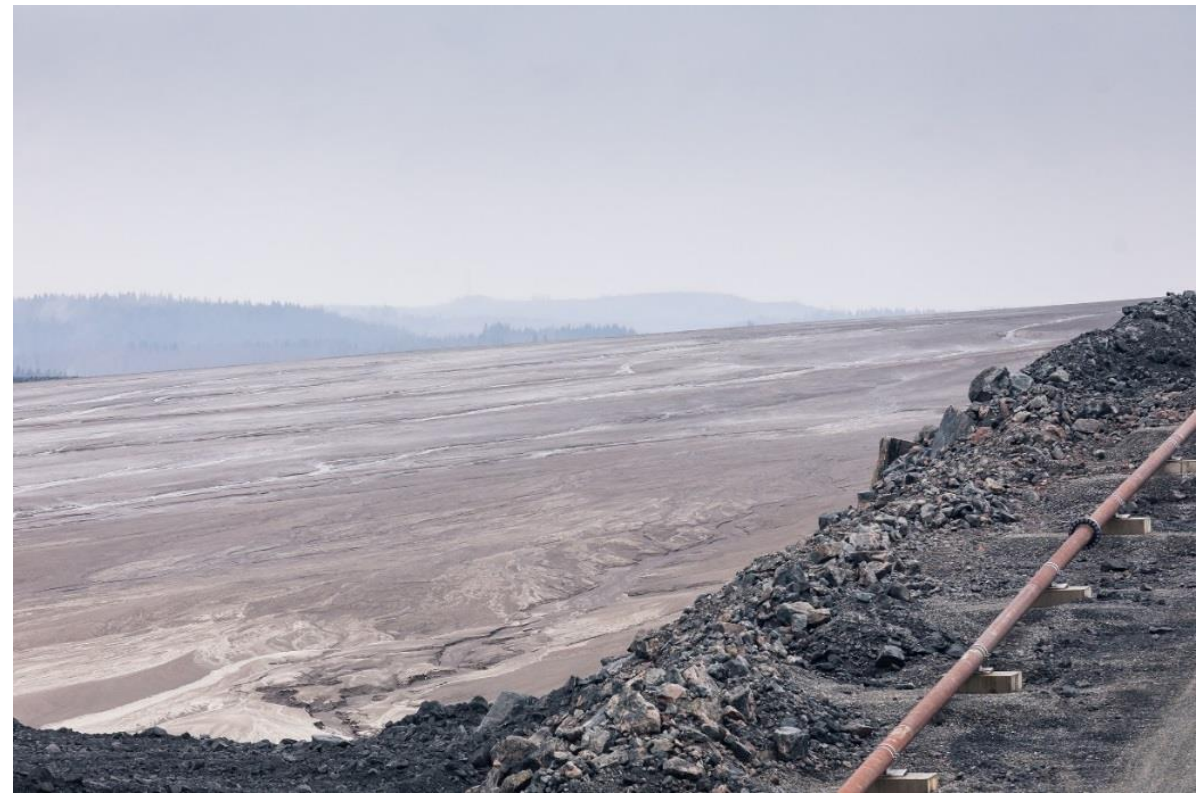

Figure 11 Example of formed beach slopes with an average steepness of $3.5^{\circ}(6.1 \%)$

\subsection{Future development}

The main controlled variables currently are underflow density and overflow solids, where the density represents the quality of the discharged slurry. In principle, the system would be even more powerful if the measurement of underflow yield stress could be incorporated into the system. Since the yield stress is a key rheological parameter of dense paste, it could directly indicate the pumping and beaching performance of the discharged slurry. In this case, there would be no need to follow the pumping performance and adjust the density target in accordance with it. Although this measurement was not included in the Yara project, it is a potential development topic for the future.

Another measurement-related development topic is to utilise more information from the incoming slurry. The main concentrator plant has a particle size analyser in its tailings line, and this information could be incorporated in the system. For example, when there are more coarse particles in the incoming flow, density target and thickener inventory level could be adjusted automatically. 
A major long-term target for Yara has been to operate the paste plant remotely from the main concentrator plant. Therefore, a lot of effort has been put into process instrumentation, automating the process sequences, and building efficient process controls. Currently, the plant still has its own 24/7 personnel, but the paste plant is already working 1-2 hrs autonomously during the shift changes. The next step would be to operate without a night shift, and then in the longer run gradually move to fully remote operation.

\section{Conclusion}

Tailings paste thickening for surface disposal is, in spite of the relatively simple process set-up, a rather complicated process to control. Very slow and complicated system dynamics and interactions between the system variables make it difficult to operate in an efficient manner. In addition, the thickener operating window is usually rather narrow and limited by the beaching properties and pumping behaviour of the discharged slurry. In addition, the changing minerology and fluctuation in the tailings feed cause challenges to the plant operation. Many of these challenges can be overcome by using adequate process instrumentation and utilising state-of-the art control techniques.

This paper presented the results from applying a multivariable, optimising control strategy to two paste thickeners at the Yara Siilinjärvi plant. The presented solution is based on a separate advanced process control platform which can be cost-effectively utilised with any customer DCS/PLC system available. With a ready-made application package, implementation is straightforward and only a minimal amount of system-specific tailoring is needed. The system at Yara is also highly integrated with the plant DCS so the operators have full access to the user interface, alarms, interlockings, history data, and documentation through the DCS displays.

The long-term follow-up demonstrates that with the optimising control, the paste thickeners can consistently run with a high and stable underflow solids content of $66-68 \%$ regardless of the challenging minerology and variation in the tailings feed rate. This results in average beach slope angles of $3.5^{\circ}(6.1 \%)$ in the tailings disposal area. Additionally, the control pushes the system towards the minimum use of flocculant, which in the long run means a remarkable 10-20\% savings in the flocculant costs. For its own part, the optimising controller also helps in underflow pumping, as it keeps the process in its operational window, with fewer manual operations required.

\section{References}

Aaltonen, J 2014, Thickened Tailings Plant Feed Parameters 2014, internal research report, Yara International, Siilinjärvi. Bemporad, A, Morari, M \& Ricker, NL 2015, Model Predictive Control Toolbox - User's Guide, The Mathworks Inc., Natick.

Kosonen, M 2004, 'Modeling and online control of paper machine wire retention', PhD dissertation, Tampere University of Technology, Tampere.

Kosonen, M, Kauvosaari, S, Gao, S \& Henriksson, B 2017, 'Performance optimization of paste thickening', in A Wu and RJ Jewell (eds), Proceedings of the 20th International Seminar on Paste and Thickened Tailings, University of Science and Technology Beijing, Beijing.

Maciejowski, JM 2002, Predictive Control with Constraints, Prentice Hall, London.

Parker, B, Rivett, T, Backeberg, T, Mclntosh, A, El-Masry, S \& Heath, A 2016, Debottlenecking of Thickeners in a Changing Environment, Outotec Oyj, Espoo.

Paterson, AJC 2004, 'High density slurry and paste tailings, transport systems', Proceedings of the International Platinum Conference 'Platinum Adding Value', The South African Institute of Mining and Metallurgy, Johannesburg, pp. 159-165.

Ruhanen, E 2014, Thickened Tailings Pilot Plant, internal research report, Yara International, Siilinjärvi.

Wikipedia 2017a, Model Predictive Control, viewed 6 October 2017, https://en.wikipedia.org/wiki/Model_predictive_control

Wikipedia 2017b, OPC Data Access, viewed 7 December 2017, https://en.wikipedia.org/wiki/OPC_Data_Access 